\title{
EXPERIENCES WITH TUNGSTEN PLASMA FACING COMPONENTS IN ASDEX UPGRADE AND JET
}

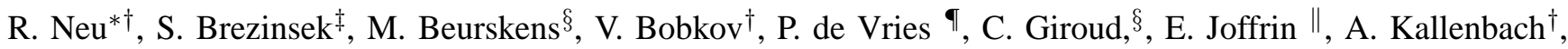 \\ G.F. Matthews ${ }^{\S}$, M.-L. Mayoral ${ }^{* \S}$, G. Pautasso ${ }^{\dagger}$, Th. Pütterich ${ }^{\dagger}$, F. Ryter ${ }^{\dagger}$, J. Schweinzer ${ }^{\dagger}$, \\ ASDEX Upgrade Team ${ }^{1}$ and JET EFDA Contributors ${ }^{2}$ \\ ${ }^{*}$ European Fusion Development Agreement, Central Support Unit, Boltzmannstr. 2, 85748 Garching, Germany \\ $\dagger$ Max-Planck-Institut für Plasmaphysik, EURATOM Association, Boltzmannstr. 2, 85748 Garching, Germany \\ $\ddagger$ IEK-4,Association EURATOM/Forschungszentrum Jülich GmbH 52425, Germany \\ $\S$ Euratom/CCFE Fusion Association, Culham Science Centre, Abingdon, OX14 3DB, UK \\ I Association EURATOM/DIFFER, Rijnhuizen P0 Box 1207 3430BE Nieuwegen, Netherlands \\ "I IRFM-CEA, Centre de Cadarache, 13108 Saint-Paul-lez-Durance, France
}

Corresponding author e-mail: Rudolf.Neu@ipp.mpg.de

\begin{abstract}
ASDEX Upgrade (AUG) has been converted to all W plasma facing components (PFCs) in 2007 and JET has implemented the ITER like wall (ILW) project (2011) using the same PFC configuration as ITER during its active phase, namely $B e$ in the main chamber and tungsten in the divertor. As a result of the all metal PFCs in both devices much less surface conditioning is needed to arrive at reproducible wall conditions. Specifically the Be PFCs of JET led to a very small low-Z content (reduction of $\mathrm{C}$ and $\mathrm{O}$ by at least a factor of 10), reducing the edge radiation in steady state operation as well as during disruptions. Both devices successfully employ massive gas injection to mitigate disruption forces and power loads to PFCs by radiating up to $100 \%$ of the available energy. Hydrogen retention is strongly reduced (AUG: factor 5, JET: factor 10) and the remaining retention is still dominated by co-deposition with residual $\mathrm{C}$ in AUG and intrinsic Be in JET. The very low edge and divertor radiation could be compensated by impurity seeding either by a single gas species $\left(\mathrm{N}_{2}\right)$ (AUG and JET) or by combining $\mathrm{N}_{2}$ and Ar (AUG) injection for divertor and main chamber radiation, respectively. The $W$ sputtering in the divertor increases when seeding small amounts of $\mathrm{N}_{2}$, but decreases for higher fluxes due to the plasma cooling provided by the nitrogen radiation. The tungsten content is controlled by the source as well as by its edge and central transport. It could be kept sufficiently small by using a minimum gas fuelling to reduce the $W$ erosion and to diminish the $W$ penetration. The control of the central $W$ transport by central (wave) heating had been well established in AUG, however in both devices the $W$ content is increased during ICRH operation most probably due to increased $W$ sputtering caused by rectified sheaths. The H-Mode threshold is reduced by $20-30 \%$ in AUG and JET, but on average the confinement is lower in JET-ILW than with C PFCs. To date it is not yet clear, whether the reduced H-Mode confinement has to be attributed to the use of W PFCs, since such a clear trend as in JET was not found in AUG. The increase of confinement with $\mathbf{N}_{2}$ seeding observed in both
\end{abstract}

1) See author list U. Stroth et al., Proc. of the 24th IAEA Fusion Energy Conf. 2012, San Diego, USA

2) See appendix of F. Romanelli et al., Proc. of the 24th IAEA Fusion Energy Conf. 2012, San Diego, USA devices hints to the fact, that low-Z impurities like carbon or nitrogen play a beneficial role for the pedestal confinement.

\section{INTRODUCTION}

In preparation of ITER and DEMO ASDEX Upgrade (AUG) has been converted to all $\mathrm{W}$ plasma facing components (PFCs) in 2007 and JET has implemented the ITER like wall project (2011) using the same PFC configuration as ITER during its active phase, namely $\mathrm{Be}$ in the main chamber and tungsten in the divertor. Using all metal/tungsten PFCs requires quite some adjustments in the way the devices are operated. This is due to the fact the amount of low- $\mathrm{Z}$ material which radiates at the plasma edge and in the divertor can be much less abundant eventually leading to high power loads at the PFCs in steady state as well as during transients making the development of radiative scenarios indispensable. This is even more true because metal PFCs can melt and therefore are much less forgiving in respect to thermal overloading as their carbon based counter-parts. Another change is necessary because of the aspired reduction of hydrogen retention: the dynamic as well as the long term retention with metal PFCs is quite different from those of C PFCs. Finally the collisional transport of tungsten differs strongly from low-Z materials potentially leading to (central) accumulation of $\mathrm{W}$, which in turn could hamper the discharge and the successful burn in a future device. This paper will provide an update on earlier works presented in [1] and [2]. The implementation of W PFCs in ASDEX Upgrade and JET will be described in Sec. II. In Sec. III the consequences of tungsten/metalic PFCs for the operation will be presented and Sec. IV will highlight the plasma behaviour and tungsten sources and transport. Finally, Sec. V will summarize the results. 


\section{Tungsten Plasma Facing Components in ASDEX UPGRADE AND JET}

In 1996, ASDEX Upgrade equipped the divertor strike point area with $\mathrm{W}$ coated tiles, demonstrating that the use of tungsten is feasible in a divertor tokamak [3]. At the same time it became clear that not only the divertor PFCs are a significant erosion source but also the main chamber carbon sources contribute significantly to the impurity content in the plasma and lead to $\mathrm{C}$ deposits in deposition dominated zones [5]. As a result the inner divertor was covered by several $\mu \mathrm{m}$ of $\mathrm{C}$ after one campaign. Consequently, the second $\mathrm{W}$ programme in AUG started in 1999 with the installation of W PFCs in the main chamber. Only in 2007 the $\mathrm{W}$ divertor tiles were installed and $100 \% \mathrm{~W}$ coverage was reached [6], representing the only full tungsten fusion device. All of the AUG W PFCs were produced by $\mathrm{W}$ coating on fine grain graphite.

The ITER-like wall (ILW) project was initiated at JET [7], [8] using beryllium (Be) as first wall and tungsten (W) as divertor armor material, to mimic the ITER choice materials for plasma facing components (PFCs) during its active phase [9]. The experiments started in summer 2011, providing the unique opportunity to address specific issues related to the parallel use of $\mathrm{Be}$ and $\mathrm{W}$ for PFCs with plasma parameters closest to those of ITER. In the main chamber bulk beryllium tiles were used for the limiters. Tungsten coated CFC [10] was installed in some higher heat flux recessed areas, as for example the neutral beam shine through areas, and beryllium coated Inconel elsewhere [11]. The JET divertor consists of W-coated CFC tiles [12] and a single toroidally continuous belt of bulk tungsten at the outer strike point [13].

\section{OPERATIONAL ISSUES}

At AUG the step by step approach pursued in the implementation of the W PFCs not only allowed to identify the role of different local $\mathrm{W}$ sources for the $\mathrm{W}$ density in the plasma and to investigate the effect of mixed materials, but also to adjust the operational procedures to a narrowing operational space (see below). On the contrary, the ILW was implemented at JET in one shutdown. As a consequence the investigations at JET benefitted from the possibility of a close comparison of operation with all C PFCs and all metallic PFCs, taking also into account earlier experiences with $\mathrm{W}$ operation ASDEX Upgrade.

\section{A. Protection of metallic PFCs}

Although the thermo-mechanical properties of $\mathrm{W}$ are similar to those of C (see for example [14]), the requirements for the monitoring of W PFCs are higher, because of its possible melting (instead of sublimation) and the larger impact of $\mathrm{W}$ influxes due to the potentially high radiative losses from the plasma core. The monitoring systems (IR thermography, VIS camera systems, emission spectroscopy) must be capable of reliably measuring heat and particle fluxes being robust in respect of reflection and emissivity variations.

At AUG, critical areas in the main chamber (for example ICRH limiters) and the $\mathrm{W}$ divertor were monitored by a multi camera

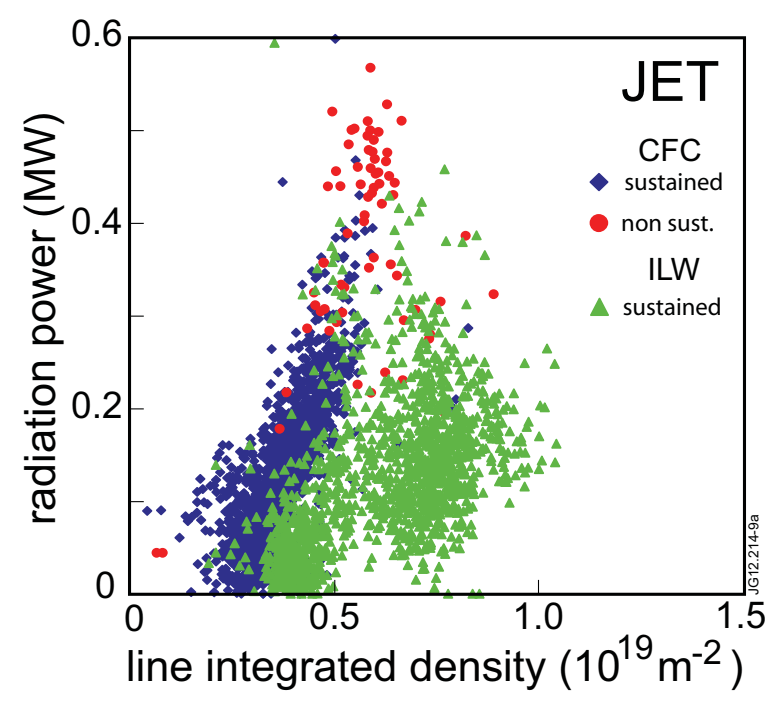

Fig. 1. Comparison of radiation during JET breakdown as function of line integrated density at $t \approx 50 \mathrm{~ms}$ (after [20]). There were no non-sustained breakdowns observed in JET ILW during the 2011/2012 campaigns.

video system [15] relying on the strongly increasing emission in the visible spectral range at temperatures above $1200^{\circ} \mathrm{C}$. Up to 12 analog video channels with multiple regions of interest (ROI) are processed and monitored on each video stream, and two safety algorithms, to detect the fraction of overheating in a ROI and for hot spot detection are implemented.

The operating limits with the JET ILW are fundamentally driven by the relatively low melting point of beryllium (1629 $\mathrm{K}$ ), the limited robustness of tungsten coatings to slow and fast thermal cycles and the thermal capabilities of the support structures for the bulk tungsten tile [16]. In order to optimize the power handling capabilities of each component (either Be or W) they were highly shaped and produced allowing tolerances only below $40 \mu \mathrm{m}$ for bulk Be in the main chamber [17] and $400 \mu \mathrm{m}$ for bulk W in the divertor [13]. The protection of the ILW was an integral part of the project from very early on. In order to achieve PFC temperature measurements in real time, a comprehensive set of bi-color pyrometers (8) and monochrome video cameras (7) with adjustable filters and thermo-couples was installed. These measurement were used to establish a map for the energy deposition at all relevant PFCs in order to allow a fast reaction of the discharge control preventing their overload [18]. In the first year of operation the protection system worked reliably, although Be melting was found in unobserved areas of the high field side Be limiters, revealing toroidal asymmetries in the main chamber power load which must be taken into account in the wall protection strategy [19]. In contrast, no melting was observed for divertor components.

\section{B. Conditioning, Breakdown and Current Ramp-Up}

After the finalization of the full $\mathrm{W}$ wall in AUG, almost two experimental campaigns were operated with new/cleaned W surfaces and without boronisation, comprising four restarts after vents. Besides oxygen, carbon still was observed in 
the plasma with concentrations in the range of $1 \%$. The carbon source is still not conclusively identified, but chemical erosion by $\mathrm{D}$ and $\mathrm{O}$ from old co-deposits on the stainless steel vacuum vessel wall is seen as a strong candidate [21]. Despite these initially high levels of low-Z impurities a quick recovery of the full $\mathrm{W}$ device could be achieved using an optimised start-up sequence. ECRH is added quite early in the discharge to increase the electron temperature and thereby the conductivity, without increasing the density to stay well below the Greenwald density limit. NBI is added from $0.3 \mathrm{~s}$ on to increase further the available heating power. In the last of these restarts (in 2008) only 5 discharges were needed to reach the pre-programmed current flattop and only four more to achieve the first H-Mode transition [22]. Even more, the reproducibility of break-down and subsequent current ramp-up is considerably improved with $\mathrm{W}$ as plasma facing material, which is exemplified by the fact that inter-discharge glow discharge cleaning is not necessary anymore and usually only a few minutes of deuterium glow are done at the start of a session. Under unboronised conditions the carbon content was only reduced by a factor of about 2 compared to operation with carbon PFCs. There are several possible C sources, with unknown relative contributions: residual carbon deposits on the stainless steel vacuum chamber walls (the area is about a factor of 3-4 larger than that of the W PFCs), some uncoated/uncovered side and back areas of the (W-coated) graphite tiles, arcs cutting through the $\mathrm{W}$ coatings or the $\mathrm{W}$ coatings themselves which can contain a few percent of $\mathrm{C}$ and which can be released by preferential sputtering. Specifically the first two of these sources could be activated by chemical erosion through oxygen and hydrogen [21]. After boronisation the oxygen and carbon concentration experienced a strong reduction (C: factor 10 , down to $0.15 \%$ (transient), O: factor 4 , down to $0.02 \%$ (persistent)) [21]. The early current rise phase has to be done in AUG in contact with a W limiter (either low or high field side), and a transition to X-point operation is made at $0.3-0.4 \mathrm{~s}$ to allow early heating during the current rise phase (typically the current flat-top is reached at $1 \mathrm{~s})$. The $\mathrm{W}$ concentrations span a large range depending on background density, machine conditions and auxiliary heating power. Typically, the concentrations range from a few times $10^{-5}$ to a few times $10^{-4}$. However, the total radiation from $\mathrm{W}\left(P_{\text {rad }} \sim n_{e}^{2} c_{W}\right)$ varies much less, because lower densities favour higher $\mathrm{W}$ concentrations and vice versa.

After installation of the ITER-like Wall in JET, a conditioning cycle of pumping, baking and glow discharge conditioning was carried out. Already, the first breakdown was successful due to the beneficial effect of Be first wall material [23] and no overnight glow discharges and no Be evaporation were necessary throughout the whole campaign in contrast to the experience with carbon walls. The profound impact of the ILW on plasma breakdown was investigated in more detail [20]. As expected, the avalanche phase was unaffected and seems to be dominated by the pre-fill pressure and its composition, but the burn-through phase strongly depends on the plasma facing material. The recycling or out-gassing properties and the

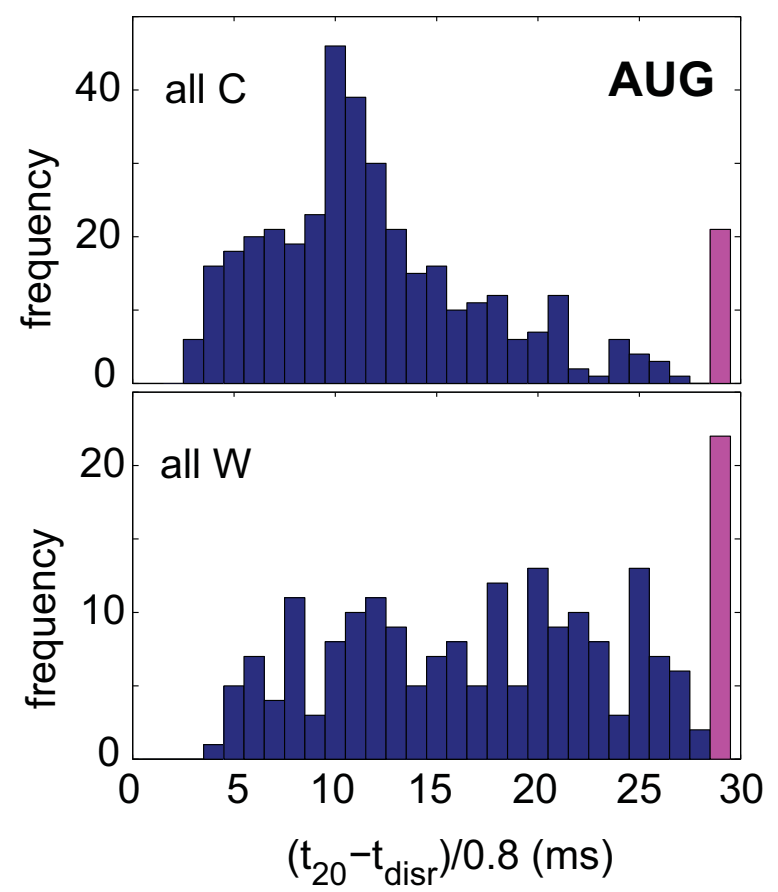

Fig. 2. Comparison of disruption times in AUG with $\mathrm{C}$ and $\mathrm{W}$ walls. For the comparison only unmitigated disruption are shown. $t_{20}-t_{d i s r}$ describes the time necessary to reach $20 \%$ of the initial $I_{p}$. The last column sums up all disruptions with $t_{20}-t_{d i s r} \geq 30 \mathrm{~ms}$.

levels of main impurities such as carbon changed significantly, affecting the density and radiation in the burn-through phase. Fig. 1 shows the radiated power during the burn-through phase versus the line integrated density. At a given density the radiation in JET with all CFC PFCs is significantly higher as with the ILW eventually leading to a non-sustained breakdown. The highest radiation levels during the burn-through phase with the ILW were obtained at the start of the ILW operation, when the carbon levels were still higher, but also during and after the use of $\mathrm{N}$ as extrinsic impurity in experiments for radiative cooling. The lower radiation efficiency of beryllium in comparison to carbon allows for a faster burn-through. In contrast to operation with C PFCs, the plasma density is determined by the amount of pre-fill gas making it more reproducible. The higher dynamic retention with the ITER-like wall (see Sec. III-C) meant that more fuelling was required to sustain the neutral and plasma density during the limiter phase.

\section{Fuel retention}

One of the main goals of the implementation of metallic walls in AUG and JET was to check the predictions for a reduced hydrogen retention from laboratory experiments.

Quite some effort was invested in AUG performing gas balance experiments and post mortem analyses of retrieved samples and tiles. A clear reduction by at least a factor of 5 was found in both kind of investigations compared to operation in C dominated AUG [24], [25]. The post mortem analysis revealed that in areas which are deposition dominated, as for example the inner divertor, hydrogen co-deposition with 
carbon (see Sec.III-B) still dominated the retention [26]. In erosion dominated areas as for example the outer divertor the $\mathrm{H}$-retention in $\mathrm{W}$ was consistent with results from laboratory devices [25] used for the extrapolation to ITER [27]. For a campaign integrated D-fluence of $\approx 5 \cdot 10^{25} \mathrm{~m}^{-2}$ the retained deuterium was about $10^{22} \mathrm{~m}^{-2}$.

For JET-ILW, first qualitative post mortem analyses of tiles extracted during the first vent suggest a large reduction of deposition and retention [28]. More quantitatively, several gas balance measurements were performed using calibrated pressure measurements and gas chromatography provided by the JET active gas handling system [29], [30]. They revealed low retention rates covering a range of 2 to $16 \cdot 10^{19} \mathrm{Ds}^{-1}$ depending on the plasma scenario. Both, in L-Mode as well as in H-Mode this represents a reduction of the retention by at least a factor of 10 compared to similar gas balance measurements performed earlier with carbon based PFCs. This again confirms qualitatively the predicted reduction of fuel retention in ITER with Be first wall and $\mathrm{W}$ divertor compared with a hypothetical full carbon ITER described in comprehensive studies [31]. The most likely mechanism for the remaining fuel retention in the JET-ILW experiments is co-deposition of fuel in Be-layers which is in line with the measured high $\mathrm{Be}$ influx from the main chamber into the inner divertor leg whose plasma-facing surfaces are a net deposition zone. Co-deposition with $\mathrm{W}$ is not of importance and implantation is the main mechanism for the retention in $\mathrm{W}$ as experiments in AUG confirmed [32], but the $\mathrm{W}$ retention plays a negligible role in comparison with the Be codeposition. Long-term outgassing has been observed in JETILW for about $100 \mathrm{~h}$ after plasma pulses with the deuterium pressure decaying as $\sim t^{-0.8}$ [33], which will lead to a further substantial reduction of the fuel content in the metallic PFCs [34].

\section{Disruption Behaviour}

The ITER-like Wall had a significant impact on disruption physics at JET [35]. The strong reduction of the $\mathrm{C}$ concentration seen from the very first ILW discharges had two direct consequences. Firstly, the onset of the disruptive "densitylimit", the MARFE development, occurs at lower divertor temperatures, well below the optimum temperature for $\mathrm{C}$ radiation, and thus it is possible to achieve higher line-averaged plasma densities [36]. Secondly, lower radiation and hence higher temperatures are observed during unmitigated ILW disruptions. This lengthened the current quench phase, increasing the impulse by the electromagnetic disruption force on the vessel. Because of the larger vessel forces and heat loads, active mitigation by massive gas injection (MGI) became a necessity for ILW operations [37]. The MGI is capable of increasing the radiation fraction close to $100 \%$, thus significantly reducing the fraction of energy conducted to the PFCs and reducing the current quench duration. On the positive side, the longer current quench rates and thus lower toroidal electric fields have made it more difficult to generate runaway electron beams [37]. Disruptions with the ILW, unmitigated and even those

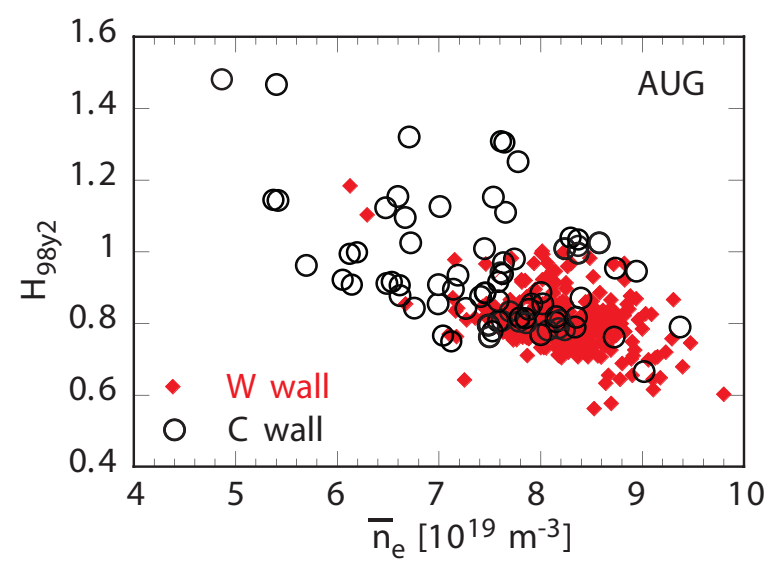

Fig. 3. H-Mode confinement factor $H_{98}(y, 2)$ versus line averaged density in baseline $\mathrm{H}$-Modes in AUG with $\mathrm{W}$ and $\mathrm{C}$ walls. The data set is restricted to discharges with $I_{p} \approx 1 \mathrm{MA}, B_{t} \approx 2.5 \mathrm{~T}$ and $3 \mathrm{MW} \leq P_{\text {loss }} \leq 7 \mathrm{MW}$.

mitigated by MGI, were found to have a negligible impact on the following discharge. So far no cases have been found where the plasma formation failed because of de-conditioning due to disruptions.

Since the transition in AUG from a full $\mathrm{C}$ to full W PFCs took 8 years and since AUG relies for several years on disruption mitigation by massive gas injection, the change of the disruption behaviour was not so evident. Only recently careful data mining revealed the same trends as for JETILW: with all W-PFCs a larger fraction of the total energy is deposited in the divertor and the current quench lasts longer than in the all C device (see Fig. 2). Similar to JET-ILW, the impact of disruptions on the machine conditioning was also strongly reduced with all W PFCs.

\section{E. ICRH compatibility with $W$ plasma facing components}

Tungsten influxes are typically extracted by measuring the brightness of a W I spectral line at $400.9 \mathrm{~nm}$ using the S/XB method [38], [39]. In AUG the main chamber W influx mainly depends on the proximity to the $\mathrm{W}$ surfaces and a compromise between high field side (HFS) sources and low field side sources has to be found. Typically, the integrated fluxes from the LFS and HFS are similar in size for similar distances, but it is more beneficial to have the LFS gap 1-2 centimetres larger than the HFS gap to reach the lowest W content [40]. Obviously, the low field side penetration of $\mathrm{W}$ is higher as also seen in Alcator C-Mod for molybdenum [41]. Comparing the absolute value of main chamber and divertor sources the time averaged divertor source is at least one order of magnitude larger in type I ELMy H-mode discharges without using ICRH [22], [40]. During ICRH operation (up to 5 MW can be routinely coupled into AUG L- and H-Mode discharges) the limiter $\mathrm{W}$ source can approach the size of that in the divertor. This increase can be explained by an increased sheath potential in front of the antennas reaching at least several tens of Volts [40]. In order to reduce this W source antenna modelling was performed [42] and as a first step the limiting structures were modified to reduce the parallel electrical field at the 
antenna edge. By this procedure some reduction of the $\mathrm{W}$ release was found, although the effect was moderate due to the fact that only one out of 4 antennas was modified [43]. From 2014 on, two newly design 3-strap antennas will be installed, which should reduce the W-influx further [43]. For the 2012 campaign the poloidal parts of the limiters of two antennas were boron coated to reduce the $\mathrm{W}$ source during ICRH without introducing $\mathrm{C}$ surfaces or other new materials [2]. The $\mathrm{W}$ increase during ICRH is substantially reduced for these antennas which demonstrates that in the case of ASDEX Upgrade the antenna limiters are the most relevant source of $\mathrm{W}$ during ICRH operation.

The available ICRH power in JET-ILW was limited to about 4 MW during 2011/2012 due to technical reasons. In LMode discharges, a strong increase of the central electron temperature during ICRH and a much larger effect on $T_{e}$ compared to the same NBI heating is observed due to the strongly localized power deposition of the ICRH. However, the radiation level during ICRH is larger by a factor of 3 and most radiation originates from the main chamber [44]. The $\mathrm{W}$ concentration in the plasma was evaluated from VUV spectroscopy [45] and the so-called "W quasicontinuum" originating from the ionization stages $\mathrm{W}^{27+}-\mathrm{W}^{35+}$ and single spectral lines from $\mathrm{W}^{39+}-\mathrm{W}^{45+}$ could be identified, which allowed extracting information on the $\mathrm{W}$ concentration profile. It strongly increases during ICRH and a large fraction of total radiation can be attributed to $\mathrm{W}$, as calculated from these concentrations by using the radiation loss parameter (see [46]). The ratio between the edge and core $\mathrm{W}$ concentrations measured by spectroscopy suggest that the $\mathrm{W}$ density profile is hollow, pointing to the beneficial effect of central ICRH in respect to the suppression of $\mathrm{W}$ accumulation as already observed in AUG [47] and in JET for Ni [48]. However, the strong increase of the $\mathrm{W}$ content was unexpected because the antenna limiters in JET are completely made out of Be. Moreover no significant increase of the $\mathrm{W}$ source in the divertor, neither at the strike point region nor at the baffle at the divertor entrance was observed, leaving the source yet to be identified [49]. In principle, a change in the (edge) transport could also lead to a higher $\mathrm{W}$ concentration, but this seems to be unlikely because copper, which is detected as a trace impurity, does not increase during ICRH. In order to shed more light on potential source, two beryllium evaporations were performed towards the end of the campaign. This resulted in a reduction by almost a factor of 2 of the total radiation during ICRH, which lasted for more than 10 discharges. Since the $\mathrm{W}$ divertor sources recovered much faster after the Be evaporations than the high $\mathrm{Z}$ content of the main plasma, one can conclude the additional $\mathrm{W}$ (and $\mathrm{Ni}$ ) sources during ICRH must not be located in areas with large particle fluxes. Indeed, tungsten surfaces exist in recessed areas in the main chamber at the high field side as well as at the low field side [50], but the detailed mechanism how the plasma can reach this areas during ICRH has still to be assessed.
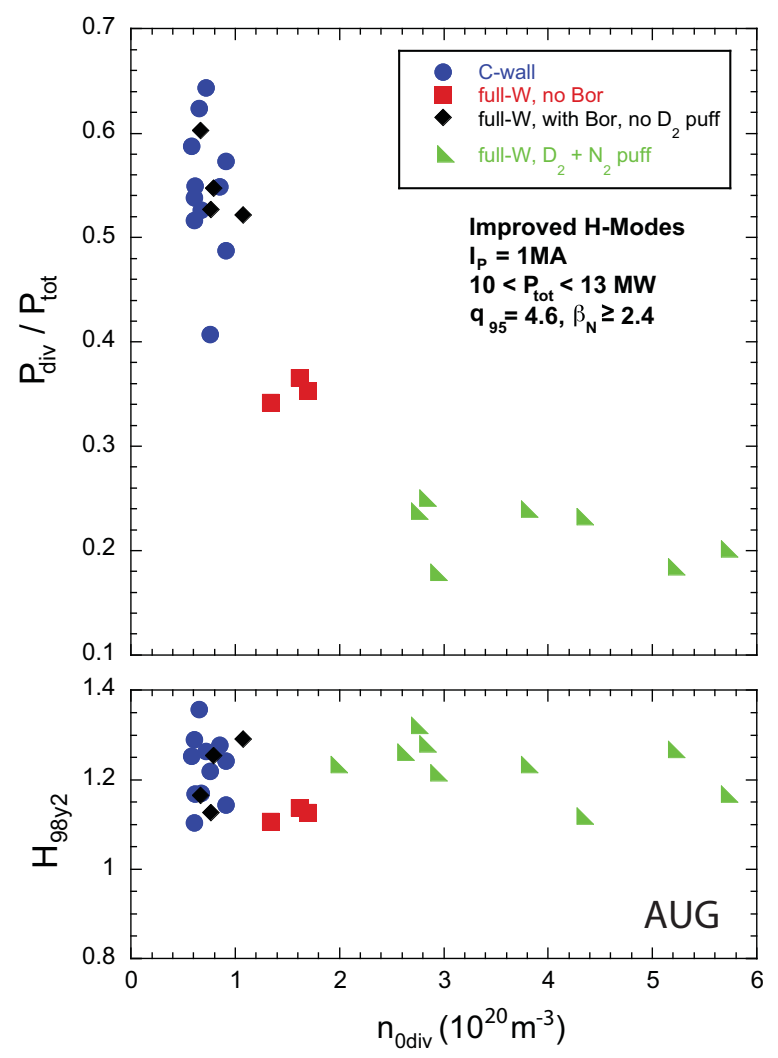

Fig. 4. Ratio of divertor deposited power $P_{\text {div }} / P_{\text {total }}$ and H-mode confinement factor $H_{98(y, 2)}$ for improved H-Modes at high $\beta_{N}$ versus the divertor neutral density $n_{0 \text { div }}$.

\section{Plasma BehaViour AND W TRANSPORT}

\section{A. H-Mode Threshold}

The L-H transition AUG is regularly checked in deuterium discharges at $I_{p}=1 \mathrm{MA}, B_{t}=2.5 \mathrm{~T}$ and a line averaged density $n_{e} \approx 5 \cdot 10^{19}$. Whereas the threshold power $(d W / d t$ is subtracted from the absorbed heating power) in the $\mathrm{C}$ dominated AUG was consistent with the ITER H-mode power threshold scaling $P_{t h r, 08}$ [51] it was reduced by about $25 \%$ when the complete W PFCs were reached [2].

Dedicated experiments have been carried out to investigate the L-H power threshold in JET-ILW, with $I_{p} / B_{t}$ and plasma shape matched to those within JET-C [52]. In JET-C, the threshold power $P_{t h r}$ defined as heating power reduced by $d W / d t$ was found to be consistent with the multi machine scaling law $P_{t h r, 08}$ [51]. Conversely, in density scans with the ILW both $P_{t h r}$ and $P_{\text {sep }}=P_{t h r}-P_{\text {rad,bulk }}$ (the bulk radiated power) increase below a minimum density, $\left(n_{e, \min } \approx 2.2 \cdot 10^{19}\right.$ $\mathrm{m}^{-3}$ at $B_{t}=1.8 \mathrm{~T}, I_{p}=1.7 \mathrm{MA}$ ) thus recovering the low density behavior observed with MkII-GB divertor (C wall) as well as in the all metal devices Alcator C-Mod [53] and AUG [54]. At plasma densities above $n_{e, m i n}, P_{t h r}$ is reduced by $\approx 30 \%$ and $P_{\text {sep }}$ by $\approx 40 \%$ in JET-ILW compared to JETC. At given edge density, the L-H transition occurs at lower edge electron temperature, $T_{e, e d g e}$ with the ILW. In NBI heated discharges, where the ion temperature $T_{i, \text { edge }}$ can be measured 
by edge charge exchange spectroscopy, $T_{i, e d g e}$ and $T_{e, \text { edge }}$ are found to be strongly coupled over the explored density range.

\section{B. Plasma Confinement}

The behaviour of the plasma confinement in baseline $\mathrm{H}$ Modes and improved H-Modes (also called 'Hybrids') in AUG was investigated independently. Fig. 3 shows the behaviour of the confinement factor $H_{98(y, 2)}$ versus the line averaged density in baseline H-Modes $\left(\beta_{N} \leq 2\right)$. The accessible density range with the W PFCs is clearly restricted to higher densities due to the necessity of a nonzero gas-puff to avoid too large W-influx (see IV-C). However, within this density range the confinement is identical to that with C PFCs. For improved $\mathrm{H}$-modes without impurity seeding, the highest confinement factors could not be reached anymore in the all W AUG, but with nitrogen seeding (see IV-D) even better performance as with C PFCs could be reached at higher densities [55], as can also be inferred from the lower part of Fig. 4 (the $\mathrm{H}$-factor is similar in all cases, but since $H_{98(y, 2)}$ scales with density, the performance of the $\mathrm{N}$-seeded discharges is higher). A detailed comparison of pedestal values under similar discharge conditions revealed that the pedestal temperatures are lower with the W PFCs similar to the observations in JET (see below), but at the same time the densities are higher resulting in a very similar pressure at the pedestal top, increasing monotonically with the applied additional heating. The reason for the higher density (at the same gas fuelling level) is not clear and it can only be speculated that a different recycling (for example the higher energy reflection coefficient) on tungsten PFCs compared to carbon based PFCs could play a role.

In JET-C, baseline ELMy H-mode plasmas achieved good normalized confinement with $H_{98(y, 2)} \approx 1$ in un-fuelled plasmas [56]. High triangularity baseline plasmas could be fuelled up to the Greenwald density without significant confinement loss, whereas gas-fuelled low triangularity plasmas showed a degraded confinement. In the case of the high- $\delta$ discharges, the maintained high confinement was attributed to the fact that the gas puff did not degrade the pedestal pressure, but rather decreased the ELM frequency, obviously compensating the increased edge transport. In JET-ILW increased fuelling was required to avoid $\mathrm{W}$ contamination as in AUG. Although there is insufficient overlap in high gas fuelling levels for the JET-C and JET-ILW experiments, the data trend suggests that the low triangularity plasmas show a similar degradation of $H_{98(y, 2)}$ with fuelling level in JET-ILW compared to JETC. However, the confinement in JET-ILW high triangularity baseline plasmas is reduced by $10-30 \%$ over the entire fuelling range. In contrast to the situation in JET-C, the ELM frequency did not drop at higher puffing levels, but rather increased [57]. It has to be noted that the degraded confinement in the high triangularity pulses is not due to an increase in plasma radiation. In the absence of carbon as a radiator, the divertor radiation is reduced in JET-ILW compared to JET-C, and in absence of strong $\mathrm{W}$ contamination, the core radiation in JET-ILW is similar or even lower than in JET-C.

The global normalized confinement of the hybrid plasmas in

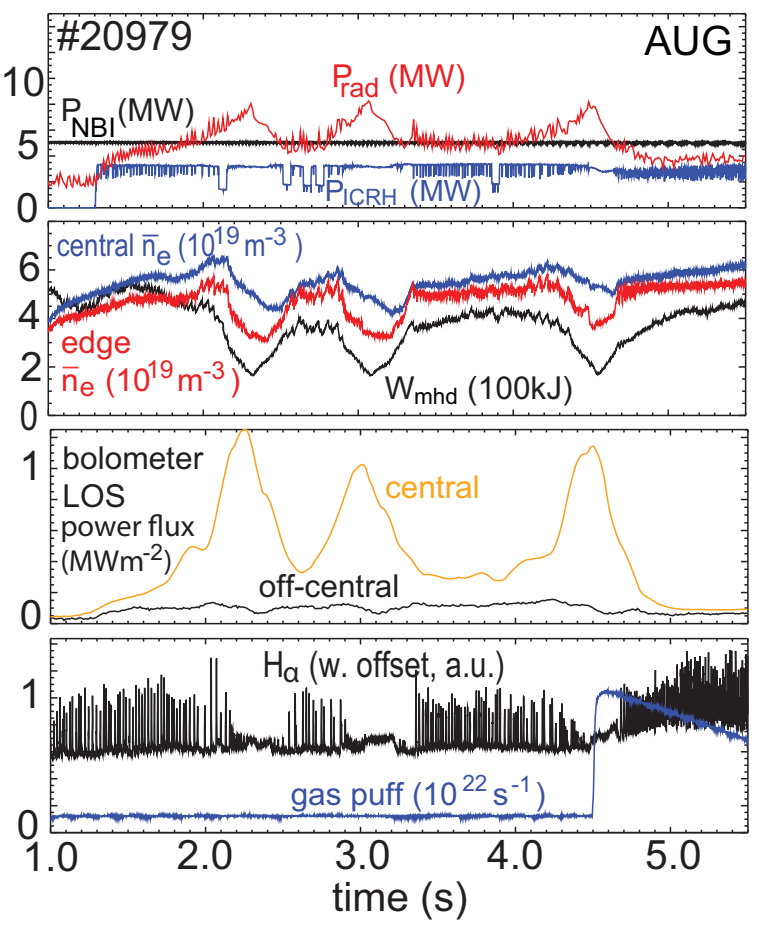

Fig. 5. L-H mode cycles in an $I_{p}=0.8 \mathrm{MA}$ discharge in AUG. The low gas puff rate (until $t=4.5 \mathrm{~s}$ ) in combination with the increased $\mathrm{W}$-influx during ICRH lead to $\mathrm{W}$ accumulation and a strong increase in the radiation power, resulting in a back transitions to L-Mode. During L-Mode the radiation is strongly reduced allowing again the transition to $\mathrm{H}-$ Mode.

JET-ILW was comparable to that in JET-C for both low and high triangularity hybrid plasmas. In JET-C the achievable confinement was best at low or zero gas fuelling, where $H_{98(y, 2)} \leq 1.4$ was achieved for both low and high triangularity. In JET-ILW zero gas puffing was not achievable due to the need to mitigate $\mathrm{W}$ accumulation. However, since the heating power in the hybrid scenario was rather high $(\approx 20 \mathrm{MW})$ and the plasma current was rather low $\left(I_{p} \leq 2 \mathrm{MA}\right)$ to achieve a high $\beta$, lower gas puffing levels than in the baseline scenarios could be used, revealing similar confinement as the JET-C experiments at similar fuelling levels. The main reason for the confinement reduction in plasmas in JET-ILW is the reduction in pedestal pressure, which sets the boundary condition for the core. In the hybrid plasmas, where also some loss of pedestal confinement was observed, it was compensated by a steepening of the core profiles, and as a consequence the global confinement approached that achieved in JET-C (see above).

\section{Role of W Source and W Transport}

The $\mathrm{W}$ content in the plasma is to a large extent governed by its transport at the edge as well as in the very centre, which means that similar W-influxes can lead to drastically different $\mathrm{W}$ concentrations. Unfuelled L-mode discharges in AUG and JET-ILW with divertor temperatures above $50 \mathrm{eV}$ are documented showing a high $\mathrm{W}$ yield [22], [58] with moderate increase of the total radiation, but no impact on plasma operation, which obviously is due to low particle 
confinement associated with L-mode. However, for keeping the overall $\mathrm{W}$ content in H-Modes low it is essential to provide an edge instability which regularly diminishes the large edge impurity density gradient due to neoclassical effects [59].

In AUG, successful flushing could be provided by increasing the frequency of natural ELMs through gas puffing and increased heating power [40] or stimulated ELMs through pellet ELM pace-making [60]. The change in the edge transport by use of magnetic perturbation coils was also sufficient to keep the $\mathrm{W}$ edge density low [61].

In JET mostly gas-puffing at rates above $10^{22} \mathrm{Ds}^{-1}$ were used to keep the W source and penetration low [62]. The ELM frequency was also increased by ELM magnetic triggering by fast vertical plasma movements ("vertical kicks") [63] and by ELM pace making [64]. Both methods were successful in clamping the $\mathrm{W}$ concentration in discharges which otherwise would be prone to $\mathrm{W}$ accumulation.

The increased $\mathrm{W}$ concentration in $\mathrm{H}$-Modes can be further amplified by neoclassical impurity accumulation in the very centre of the plasma and in AUG the ratio of $\mathrm{W}$ concentration $\left(c_{W}\right)$ on axis can reach values which are larger by a factor 50 compared to the ones at the pedestal top [65]. This peaking is the result of the interplay of neoclassical effects with turbulent processes and macroscopic transport events as ELMs or sawteeth. If the $\mathrm{W}$ content is high enough the radiative losses can even influence the transport in the background plasma. In Fig. 5 several phases with accumulations within one discharge are shown. The accumulation becomes evident from the evolution of a very peaked radiation profile indicated by the line integrated radiation measured by a central and an offcentral bolometer channel. The large bulk radiation reduces the $P_{\text {loss }}$ and thereby the ELM frequency, which in turn leads to a less efficient flushing of W. Finally the strong central radiation leads to a back transition a L-Mode, which strongly reduces the density and the $\mathrm{W}$ content. The reduced radiation allows again the transition to H-Modes and the cycle starts over again. Only after $4.5 \mathrm{~s}$ where the $\mathrm{D}$ gas puff is increased by a factor of 6 the radiation and its peaking are strongly reduced. It should be noted that although the total radiated power approached almost $100 \%$ of the heating power no disruption occurred.

It could be shown early in the AUG $\mathrm{W}$ programme that central deposition of heating power is very beneficial in reducing the W-peaking [65], [66]. This heating can be provided either by ICRH or ECRH and even the deposition profile of beams using different acceleration voltage [3] or injection geometry plays a role. The amount of necessary local heating depends delicately on the local $\mathrm{W}$ concentration itself which was tested in similar accumulating discharges with different timing of an ECRH heating pulse [47]. Similarly, there is a tradeoff between reducing the overall $\mathrm{W}$ density by gas puffing and the central heating to prevent accumulation [60] (see also Fig. 5). Detailed transport investigations in AUG using tracer impurities show that the local heating leads to a strong increase of anomalous transport [67], [68]. However, for the most central ECR-heated discharge analysed, the resulting strong positive (outward) convection is probably not of turbulent nature but could be

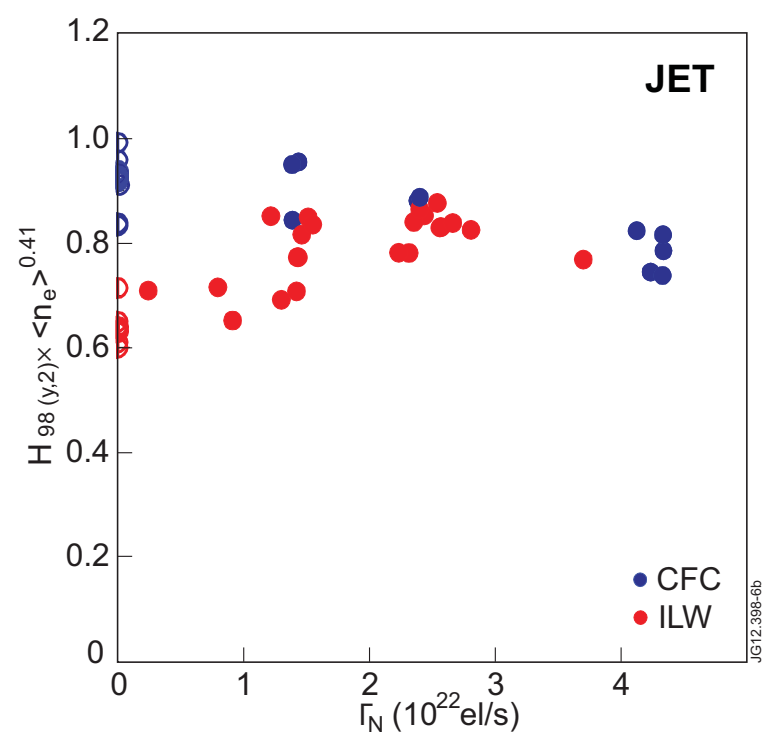

Fig. 6. Confinement (density dependence removed from the $H_{98}(y, 2)$ scaling) versus $\mathrm{N}_{2}$-seeding rate in JET [70].

caused by the strong MHD activity present within the $\mathrm{q}=1$ surface.

Although central heating by ICRH and NBI in JET was marginal for baseline H-modes in the first phase of ILW operation due to initial technical limitations on ICRH power and beam voltage, gas puffing and central heating were successfully applied to suppress $\mathrm{W}$ accumulation and excessive $\mathrm{W}$ concentration at lower currents. Moreover it could be shown in [69] that the local power balance in the plasma centre plays a key role in the accumulation cycle.

\section{Impurity seeding in high power operation in L- or H-mode}

In order to reduce the divertor power load, impurity seeding is necessary in AUG and JET and will be mandatory in ITER and DEMO. At low seeding rates enhanced sputtering of $\mathrm{W}$ by seeding impurities $(\mathrm{N}, \mathrm{Ar})$ occurs when the radiation cooling is not yet sufficient, while going towards high seed impurity fluxes in L-mode the $\mathrm{W}$ sputtering can be reduced below the initial value [71]. In type I ELMy H-mode however, the $\mathrm{W}$ source becomes determined by the sputtering during the ELM bursts (see Sec. IV-C) and while seeding can eliminate the inter-ELM source, the total $\mathrm{W}$ source either increases with nitrogen seeding [70] (JET) or stays about constant [72] (AUG). Only in the type III ELMy H-mode regime, which was achieved in AUG by strong deuterium gas puffing and $\mathrm{N}$ seeding the $\mathrm{W}$ divertor source was strongly suppressed [73]. The top part of Fig. 4 shows the fraction of the total heating power deposited in the divertor in high power discharges in AUG. In clean unseeded discharges (boronised walls) about $60 \%$ of the total power is deposited in the divertor while with nitrogen seeding in combination with substantial gas puffing (increase of the neutral density in the divertor $n_{\text {odiv }}$ ) it can be reduced by a factor of 3 . The feed-back controlled impurity seeding either by a single gas species $\left(\mathrm{N}_{2}\right)$ or by combining $\mathrm{N}_{2}$ 
and $\mathrm{Ar}$ injection for divertor and main chamber radiation [74], allowed for a reduction of the divertor load below $5 \mathrm{MWm}^{-2}$ at additional heating power above $20 \mathrm{MW}$.

In addition to the divertor power reduction, seeding with nitrogen can improve the pedestal parameters and overall energy confinement in both devices [70], [75]. Fig. 6 shows the $H_{98(y, 2)}$ factor (where the density dependence is removed to compensate for the higher densities typically achieved with ILW) for high $\delta$ discharges with the ILW and with all CFC PFCs in JET for different levels of N seeding. Whereas without $\mathrm{N}$ seeding the confinement is up to $30 \%$ lower with the ILW open symbols on the ordinate), similar confinement is reached at $\mathrm{N}$ seeding rates above $10^{22} \mathrm{el} / \mathrm{s}$. The effect of nitrogen on the confinement is even more pronounced in AUG where even at very high puffing rates $H_{98(y, 2)}>1$ is reached (see lower part of Fig. 4. In both devices the improved confinement with $\mathrm{N}$ seeding originates from an increased pedestal confinement [55], [57]. This suggests that the edge impurity composition has a strong effect on the pedestal stability and that nitrogen replaces carbon as a low- $Z$ impurity. Indeed, experiments in AUG using methane as seeding gas show a similar confinement improvement as with nitrogen.

Despite the very clear experimental evidence for the confinement improvement, there is no settled theoretical explanation yet. Recent non-linear gyro-kinetic simulations using GENE showed in N seeded AUG discharges a shift of the ITG critical $R / L_{T i}$ towards higher values [76]. This is caused by the reduction of the ITG mode due to deuterium dilution. In the core, this effect is completely compensated by the observed higher $T_{e, i}$ values of $\mathrm{N}$ seeded discharges, since the heat flux grows above the critical $R / L_{T i}$ as $T_{i}^{5 / 2}$. Also in JET the confinement increase is governed by a higher pedestal, however the observed $Z_{\text {eff }}$ variation is much smaller than that in AUG [77].

\section{SUMmARY AND CONCLUSIONS FOR ITER}

In preparation of ITER and DEMO ASDEX Upgrade has been converted to all $\mathrm{W}$ plasma facing components in 2007 and JET has implemented the ITER like wall project (2011) using the same PFC configuration as ITER during its active phase, namely $\mathrm{Be}$ in the main chamber and tungsten in the divertor. Operation with all metal/tungsten PFCs requires significant adjustments in the way the devices are operated. In order to prevent melting of the PFCs dedicated diagnostics and algorithms have been implemented in both devices. The experience gained in the monitoring and protection techniques are specifically relevant for ITER since the low emissivity and the large reflectivity of metallic surfaces make higher demands than the carbon based PFCs.

Since the JET main chamber PFCs consists of Be, also the specific properties of this choice compared to all W PFCs could be studied. An outstanding benefit of the Be PFCs is the very small low- $\mathrm{Z}$ content (reduction of $\mathrm{C}$ and $\mathrm{O}$ by at least a factor of 10) from the beginning of the operation, which allowed operating JET for one year without any surface conditioning. A similar suppression of low- $Z$ impurities was observed in
AUG after boronisation. Since the main chamber is the main area of plasma wall interaction during the limiter current rampup, the JET results should provide significant guidance for an all metal ITER. The expected reproducible wall conditions and the low $Z_{\text {eff }}$ will allow a reliable breakdown and simplify the early phases of the current ramp even at the lower loop voltage foreseen in ITER.

As a consequence of the low- $\mathrm{Z}$ content in JET, the intrinsic radiation during disruptions was much lower. This resulted in higher power loads to the PFCs as well as in larger disruption forces, which could both successfully reduced by massive gas injection. Therefore ITER should be equipped with disruption avoidance and mitigation tools already early during its L-Mode operational phase because the strong reduction of intrinsic radiation during the thermal quench can further increase the expected power loads of unmitigated ITER disruptions as extrapolated from devices with carbon PFCs [9] to values exceeding the limit of the Be armour material.

The very low edge and divertor radiation, which successfully could be compensated in AUG by feed-back controlled impurity seeding, either by a single gas species $\left(\mathrm{N}_{2}\right)$ or by combining $\mathrm{N}_{2}$ and $\mathrm{Ar}$ injection for divertor and main chamber radiation. This yielded a reduction of the divertor load below $5 \mathrm{MWm}^{-2}$ at additional heating power above $20 \mathrm{MW}$, still preserving good confinement. Depending on the degree of the reduction of the divertor electron temperature by the $\mathrm{N}$ radiation, the ELM averaged W sputtering stayed constant or could even be decreased.

In both devices the hydrogen retention is strongly reduced (AUG: factor 5, JET: factor 10) and the remaining retention is still dominated by co-deposition with residual C in AUG and intrinsic Be in JET. Although one has to await the quantitative results of the post mortem analyses of the JET PFCs for a final assessment of the H-retention in ITER, the extrapolation of the JET gas balance measurements taking into account the different fluxes and surface areas in JET and ITER [78] confirms the predictions of [31].

The tungsten content in both devices is controlled by the source as well as by its edge and central transport. It could be kept sufficiently small by using a minimum gas fuelling to reduce the $\mathrm{W}$ erosion and to diminish the $\mathrm{W}$ penetration. Predictions for the absolute $\mathrm{W}$ content in ITER are difficult. However, if the $\mathrm{W}$ transport is governed by neoclassical effects in regions with low turbulent transport (plasma centre, edge transport barrier) as it is found in AUG, only a very moderate central peaking of the central W-density [65] and a very efficient $\mathrm{W}$ screening by the edge transport barrier [79] is expected. The control of the central $\mathrm{W}$ transport by central (wave) heating had been well established in AUG, however in both devices the $\mathrm{W}$ content is increased during ICRH operation most probably due to increased $\mathrm{W}$ sputtering caused by rectified sheaths. The influence of ICRF on the $\mathrm{W}$ source in ITER is not easily to be predicted due to the different behaviour in AUG (mostly W limiter source) and JET (probably distributed main chamber/divertor source). A way forward will be the comparison of measured W source 
profiles with the results of sophisticated RF-codes in order to validate them. An important benchmark will be the reactivation of the JET ITER-like antennas in 2014, which are predicted to cause significantly less impurity influx in JET than the currently existing ones [49].

The H-Mode threshold is consistently reduced by $\approx 30 \%$ in AUG and JET. If this extrapolates to ITER it would significantly ease the H-mode access in ITER, lowering the requirements for additional heating. On the other hand the average confinement is lower in JET-ILW baseline H-Mode discharges than with C PFCs. To date it is not yet clear, whether the reduced H-Mode confinement has to be attributed to the use of W PFCs, since such a clear trend as in JET was not found in AUG. The $Q=10$ milestone in the ITER baseline scenario is based on the assumption of the achievement of $H_{98(y, 2)}=1$, which is extrapolated from current scalings. A reduction of the $\mathrm{H}$-factor down to 0.8 would result in $Q \approx 5$ [80]. Therefor further investigations, specifically in JET, have to concentrate on the understanding of the cause of the reduced confinement in order to provide tools for recovery. Specifically, the increase of confinement with $\mathrm{N}_{2}$ seeding consistently observed in both devices hints to the fact, that low- $\mathrm{Z}$ impurities like carbon or nitrogen play a beneficial role for the pedestal confinement. Another route to be followed in ITER could be to investigate hybrid discharges which seem to have an easier access to higher confinement under the conditions of all metal PFCs.

\section{ACKNOWLEDGMENT}

The author would like to thank the ASDEX Upgrade team and the JET-EFDA contributors for their strong support. This work was supported by EURATOM and carried out within the framework of the European Fusion Development Agreement. The views and opinions expressed herein do not necessarily reflect those of the European Commission.

\section{REFERENCES}

[1] G. Matthews, JET EFDA Contributors, and ADSEX Upgrade Team, "Plasma operation with an all metal first-wall: comparison of an ITER-like wall with a carbon wall in JET," Journal of Nuclear Materials, vol. 438 Supplement, pp. S2-S10, 2013.

[2] R. Neu, A. Kallenbach, M. Balden, V. Bobkov, J. Coenen et al., "Overview on plasma operation with a full tungsten wall in ASDEX Upgrade," Journal of Nuclear Materials, vol. 438 Supplement, pp. S34-S41, 2013.

[3] R. Neu, K. Asmussen, K. Krieger, A. Thoma, H.-S. Bosch et al., "The tungsten divertor experiment at ASDEX Upgrade," Plasma Physics and Controlled Fusion, vol. 38, pp. A165-A179, 1996.

[4] R. Neu, H. Maier, E. Gauthier, H. Greuner, T. Hirai et al., "Investigation of tungsten coatings on graphite and CFC," Physica Scripta, vol. T128, pp. 150-156, 2007.

[5] K. Krieger, H. Maier, R. Neu, and ASDEX Upgrade Team, "Conclusions about the use of tungsten in the divertor of ASDEX Upgrade," Journal of Nuclear Materials, vol. 266-269, pp. 207-216, 1999.

[6] R. Neu, M. Balden, V. Bobkov, R. Dux, O. Gruber, et al., "Plasma wall interaction and its implication in an all tungsten divertor tokamak," Plasma Physics and Controlled Fusion, vol. 49, no. 12B, pp. B59-B70, 2007.

[7] J. Pamela, G. Matthews, V. Philipps, and R. Kamendje, "An ITER-like wall for JET," J. Nucl. Mater, vol. 363-365, pp. 1 - 11, 2007.

[8] G. Matthews, P. Edwards, T. Hirai, M. Kear, A. Lioure et al.,"Material aspects in the ITER-like wall project," Physica Scripta, vol. T128, pp. 137-143, 2007.
[9] R. Pitts, S. Carpentier, F. Escourbiac, T. Hirai, V. Komarov et al., "Physics basis and design of the ITER plasma-facing components," Journal of Nuclear Materials, vol. 415, no. 1, Supplement, pp. S957 S964, 2011.

[10] C. Ruset, E. Grigore, H. Maier, R. Neu, X. Li, et al., "W coatings deposited on CFC tiles by combined magnetron sputtering and ion implantation technique," Physica Scripta, vol. T128, pp. 171-174, 2007.

[11] T. Hirai, H. Maier, M. Rubel, P. Mertens, R. Neu et al., "R and D on full tungsten divertor and beryllium wall for JET ITER-like wall project," Fusion Engineering and Design, vol. 82, no. 15-24, pp. 1839 - 1845, 2007.

[12] H. Maier, R. Neu, H. Greuner, B. Böswirth, M. Balden et al., "Qualification of tungsten coatings on plasma-facing components for JET," Physica Scripta, vol. T138, p. 014031, 2009.

[13] P. Mertens, "Detailed design of a solid tungsten divertor row for JET in relation to the physics goals," Physica Scripta, vol. 2011, no. T145, p. 014002, 2011.

[14] R. Neu, "High-z plasma facing components in fusion devices: Boundary conditions and operational experiences," Physica Scripta, vol. T123, pp. 33-44, 2006.

[15] A. Herrmann, R. Drube, T. Lunt, P. de Marné, and ASDEX Upgrade Team, "Real-time protection of in-vessel components in ASDEX Upgrade," Fusion Engineering and Design, vol. 86, no. 6-8, pp. 530-534, 2011.

[16] V. Riccardo, M. Firdaouss, E. Joffrin, G. Matthews, P. Mertens et al., "Operational limits for the ITER-like wall in JET," Physica Scripta, vol. 2009, no. T138, p. 014033, 2009.

[17] I. Nunes, V. Riccardo, P. Lomas, P. de Vries, D. Alves et al., "Be tile power handling and main wall protection," in Proc. "24th IAEA Fusion Energy Conference", San Diego, USA, 2012, pp. FTP/2-1Rb.

[18] G. Arnoux, S. Devaux, D. Alves, I. Balboa, C. Balorin, et al., "A protection system for the JET ITER-like wall based on imaging diagnostics," Rev. Scient. Instr., vol. 83, p. 10D727, 2012.

[19] G. Arnoux, I. Balboa, M. Clever, S. Devaux, P. D. Vries, et al., "Power handling of the JET ITER-like wall (limiter and divertor)," in 14th Int. Conf. on Plasma-Facing Materials and Components for Fusion Applications, May 13-17, 2013 Jülich, Germany.

[20] P. de Vries, A. Sips, H. Kim, P. Lomas, F. Maviglia et al., "Characterisation of plasma breakdown at JET with a carbon and ITER-like wall," Nuclear Fusion, vol. 53, no. 5, p. 053003, 2013.

[21] A. Kallenbach, R. Dux, M. Mayer, R. Neu, T. Pütterich et al., "Nonboronized compared with boronized operation of ASDEX Upgrade with full-tungsten plasma facing components," Nuclear Fusion, vol. 49, no. 4, p. 045007, 2009.

[22] R. Neu, V. Bobkov, R. Dux, J. C. Fuchs, O. Gruber et al., "Ten years of W programme in ASDEX Upgrade - challenges and conclusions," Physica Scripta, vol. T138, p. 014038 (6pp), 2009.

[23] D. Douai, S. Brezinsek, H. Esser, E. Joffrin, T. Keenan et al., "Wall conditioning of JET with the ITER-like wall," Journal of Nuclear Materials, vol. 438, Supplement, pp. S1172 - S1176, 2013.

[24] V. Rohde, M. Mayer, V. Mertens, R. Neu, K. Sugiyama, and ASDEX Upgrade Team, "Dynamic and static deuterium inventory in ASDEX Upgrade with tungsten first wall," Nuclear Fusion, vol. 49, no. 8, p. 085031 (9pp), 2009.

[25] K. Sugiyama, K. Krieger, M. Mayer, S. Lindig, M. Balden et al., "Deuterium retention in bulk tungsten exposed to the outer divertor plasma of ASDEX Upgrade," Physica Scripta, vol. 2011, no. T145, p. 014033, 2011.

[26] M. Mayer, V. Rohde, K. Sugiyama, J. L. Chen, X. Gong, et al., "Carbon balance and deuterium inventory from a carbon dominated to a full tungsten ASDEX Upgrade," Journal of Nuclear Materials, vol. 390-391, pp. 538-543, 2009.

[27] B. Lipschultz et al., "An assessment of the current data affecting tritium retention and its use to project towards tritium retention in ITER," Plasma Science and Fusion Center, MIT, Cambridge, USA, Rep. PSFC/RR-10-4, 2010

[28] J. P. Coad, E. Alves, C. Ayres, N. Barradas, A. Baron-Wiechec et al., "Surface analysis of tiles and samples exposed to the first JET campaigns with the ITER-like wall," in 14th Int. Conf. on Plasma-Facing Materials and Components for Fusion Applications, May 13-17, 2013 Jülich, Germany.

[29] T. Loarer, S. Brezinsek, V. Philipps, J. Bucalossi, D. Douai et al., "Comparison of long term fuel retention in JET between carbon and the 
ITER-like wall," Journal of Nuclear Materials, vol. 438, Supplement, pp. S108 - S113, 2013.

[30] S. Brezinsek, T. Loarer, V. P. Philipps, H. G. Esser, S. Grünhagen et al., "Fuel retention studies with the ITER-like wall in JET," in submitted to Nuclear Fusion and Proc. "24th IAEA Fusion Energy Conference", San Diego, USA, 2012, pp. EX/4-1.

[31] J. Roth, E. Tsitrone, A. Loarte, T. Loarer, G. Counsell et al., "Recent analysis of key plasma wall interactions issues for ITER," J. Nucl. Mater., vol. 390-391, pp. 1-9, 2009.

[32] K. Sugiyama, M. Mayer, V. Rohde, M. Balden, T. Durbeck et al., "Deuterium inventory in the full-tungsten divertor of ASDEX Upgrade," Nuclear Fusion, vol. 50, no. 3, p. 035001 (8pp), 2010.

[33] V. Philipps, T. Loarer, H. Esser, S. Vartanian, U. Kruezi et al.,"Dynamic fuel retention and release under ITER like wall conditions in JET," Journal of Nuclear Materials, vol. 438, Supplement, pp. S1067 S1071, 2013.

[34] V. Philipps, T. Loarer, G. Matthews, S. Brezinsek, and S. G. Romanelli, "Fuel retention and long-term outgassing in JET with the ITER-like wall," presented at 14th Int. Conf. on Plasma-Facing Materials and Components for Fusion, Aachen, submitted to Physica Scripta, 2013.

[35] P. C. de Vries, G. Arnoux, A. Huber, J. Flanagan, M. Lehnen et al., "The impact of the ITER-like wall at JET on disruptions," Plasma Physics and Controlled Fusion, vol. 54, no. 12, p. 124032, 2012.

[36] M. Groth, S. Brezinsek, P. Belo, G. Corrigan, D. Harting et al., "Target particle and heat loads in low-triangularity 1-mode plasmas in JET with carbon and beryllium/tungsten walls," Journal of Nuclear Materials, vol. 438, Supplement, pp. S175 - S179, 2013.

[37] M. Lehnen, G. Arnoux, N. Baumgarten, S. Brezinsek, J. Flanagan et al., "Impact and mitigation of disruptions with the ITER-like wall in JET," in Proc. "24th IAEA Fusion Energy Conference", San Diego, USA, 2012, pp. EX/9-1.

[38] R. Dux, A. Herrmann, A. Kallenbach, R. Neu, J. Neuhauser et al., "Plasma surface interaction with tungsten in ASDEX Upgrade," Journal of Nuclear Materials, vol. 337-339, pp. 852-856, 2005.

[39] G. van Rooij, J. Coenen, L. Aho-Mantila, M. Beurskens, S. Brezinsek et al., "Characterization of tungsten sputtering in the JET divertor," in Proc. "24th IAEA Fusion Energy Conference", San Diego, USA, 2012, pp. EX/P5-05.

[40] R. Dux, V. Bobkov, A. Herrmann, A. Janzer, A. Kallenbach et al., "Plasma-wall interaction and plasma behaviour in the non-boronised all tungsten ASDEX Upgrade," Journal of Nuclear Materials, vol. 390-391, pp. 858-863, 2009.

[41] B. Lipschultz, D. Pappas, B. LaBombard, J. Rice, D. Smith, and S. Wukitch, "A study of molybdenum influxes and transport in Alcator C-Mod," Nucl. Fusion, vol. 41, pp. 585 - 596, 2001.

[42] V. Bobkov, F. Braun, R. Dux, A. Herrmann, L. Giannone et al., "Assessment of compatibility of ICRF antenna operation with full W wall in ASDEX Upgrade," Nuclear Fusion, vol. 50, no. 3, p. 035004 (11pp), 2010.

[43] V. Bobkov, M. Balden, F. Braun, R. Dux, A. Herrmann et al., "ICRF operation with improved antennas in a full W-wall ASDEX Upgrade, status and developments," in Proc. of the 24rd IAEA Fusion Energy Conference, San Diego, USA, vol. IAEA-CN-197. Vienna: IAEA, 2012, pp. EX/P5-19.

[44] D. V. Eester, E. Lerche, P. Jacquet, V. Bobkov, A. Czarnecka et al., "Characterization of ion cyclotron resonance heating in presence of the ITER-like wall in JET," in Europhysics Conference Abstracts (CD-ROM, Proc. of the 39th EPS Conference on Controlled Fusion and Plasma Physics, Stockholm), vol. 36F. Geneva: EPS, 2012, p. P1.094.

[45] T. Pütterich, R. Neu, R. Dux, A. D. Whiteford, M. G. O'Mullane, and ASDEX Upgrade Team, "Modelling of measured tungsten spectra from ASDEX Upgrade and predictions for ITER," Plasma Physics and Controlled Fusion, vol. 50, no. 8, p. 085016, 2008.

[46] T. Pütterich, R. Neu, R. Dux, A. Whiteford, M. O'Mullane et al., "Calculation and experimental test of the cooling factor of tungsten," Nuclear Fusion, vol. 50, no. 2, p. 025012 (9pp), 2010.

[47] R. Neu, R. Dux, A. Geier, H. Greuner, K. Krieger et al., "New results from the tungsten programme at ASDEX Upgrade," Journal of Nuclear Materials, vol. 313-316, pp. 116-126, 2003.

[48] M. Valisa, L. Carraro, I. Predebon, M. Puiatti, C. Angioni et al., "Metal impurity transport control in JET H-mode plasmas with central ion cyclotron radiofrequency power injection," Nuclear Fusion, vol. 51, no. 3, p. 033002, 2011.
[49] V. Bobkov, G. Arnoux, S. Brezinsek, J. Coenen, L. Colas et al., "ICRF specific plasma wall interactions in JET with the ITER-like wall," Journal of Nuclear Materials, vol. 438, Supplement, pp. S160 - S165, 2013.

[50] G. Matthews, M. Beurskens, S. Brezinsek, M. Groth, E. Joffrin et al., "JET ITER-like wall - overview and experimental programme," Physica Scripta, vol. T145, p. 014001, 2011.

[51] Y. R. Martin, T. Takizuka, and the ITPA CDBM H-mode Threshold Database Working Group, "Power requirement for accessing the H-mode in ITER," Journal of Physics: Conference Series, vol. 123, no. 1, p. 012033, 2008.

[52] C. Maggi, G. Calabro, E. Delabie, M. Groth, N. Hawkes et al., "The H-mode threshold in JET with the ITER-like wall," in Europhysics Conference Abstracts (CD-ROM, Proc. of the 39th EPS Conference on Controlled Fusion and Plasma Physics, Stockholm), vol. 36F. Geneva: EPS, 2012, p. O3.108.

[53] J. Snipes, M. Greenwald, A. Hubbard, J. Hughes, B. LaBombard, and J. Rice, "Plasma current and toroidal field dependence of the $\mathrm{H}$-mode threshold low density limit on Alcator C-mod," in Europhysics Conf. Abstracts (CD-ROM)Proc. 35th EPS Plasma Physics Conf. (Hersonissos, Greece), P. Lalousis and S. Moustaizis, Eds., vol. 32D. EPS, 2008, p. P1.074.

[54] F. Ryter, T. Pütterich, M. Reich, A. Scarabosio, E. Wolfrum et al., "H-mode threshold and confinement in helium and deuterium in ASDEX Upgrade," Nuclear Fusion, vol. 49, p. 062003, 2009.

[55] J. Schweinzer, A. Sips, G. Tardini, P. Schneider, R. Fischer et al., "Confinement of 'improved H-modes' in the all-tungsten ASDEX Upgrade with nitrogen seeding," Nuclear Fusion, vol. 51, no. 11, p. 113003, 2011

[56] M. Beurskens, L. Frassinetti, C. Challis, T. Osborne, P. Snyder et al., "Comparison of hybrid and baseline ELMy H-mode confinement in JET with the carbon wall," Nuclear Fusion, vol. 53, no. 1, p. 013001, 2013.

[57] M. Beurskens, L. Frassinetti, C. Maggi, G. Calabro, B. Alper et al., "L-H power threshold, pedestal stability and confinement in JET with a metallic wall," in submitted to Nuclear Fusion and Proc. "24th IAEA Fusion Energy Conference", San Diego, USA, Vienna, 2012, pp. EX/P720.

[58] J. Coenen, G. van Rooij, L. Aho-Mantila, S. Brezinsek, M. Clever et al., "Tungsten erosion in the all-metal tokamaks JET and ASDEX Upgrade," in Europhysics Conference Abstracts (CD-ROM, Proc. of the 39th EPS Conference on Plasma Physics, Stockholm, Sweden, 2012), ser. ECA, S. Ratynskaya, L. Blomberg, and A. Fasoli, Eds., vol. 36F. Geneva: European Physical Society, 2012, p. P1.036.

[59] R. Dux, A. Janzer, T. Pütterich, and ASDEX Upgrade Team, "Main chamber sources and edge transport of tungsten in $\mathrm{H}$-mode plasmas at ASDEX Upgrade," Nuclear Fusion, vol. 51, no. 5, p. 053002, 2011.

[60] A. Kallenbach, R. Neu, R. Dux, H.-U. Fahrbach, J. C. Fuchs et al., "Tokamak operation with high-Z plasma facing components," Plasma Physics and Controlled Fusion, vol. 47, no. 12B, pp. B207-B222, 2005.

[61] R. Neu, ASDEX Upgrade Team, EU PWI Taskforce, and JET EFDA Contributors, "Preparing the scientific basis for an all metal ITER," Plasma Physics and Controlled Fusion, vol. 53, no. 12, p. 124040, 2011.

[62] E. Joffrin, J. Bucalossi, P. Lomas, F. Rimini, R. Neu et al., "Scenarios development at JET with the new ITER-like wall," in Proc. "24th IAEA Fusion Energy Conference", San Diego, USA, 2012, pp. EX/1-1.

[63] E. de la Luna, R. Sartori, G. Saibene, P. Lomas, V. Parail et al., "The effect of ELM mitigation methods on the access to high $\mathrm{H}$-mode confinement $(\mathrm{H} 98 \approx 1)$ on JET," in Proc. "24th IAEA Fusion Energy Conference", San Diego, USA, 2012, pp. EX/6-1.

[64] P. Lang, D. Frigione, A. Géraud, T. Alarcon, P. Bennett et al., "ELM pacing and trigger investigations at JET with the new ITER-like wall," Nuclear Fusion, vol. 53, no. 7, p. 073010, 2013.

[65] R. Neu, R. Dux, A. Kallenbach, T. Pütterich, M. Balden et al., "Tungsten: An option for divertor and main chamber plasma facing components in future fusion devices," Nuclear Fusion, vol. 45, no. 3 , pp. 209-218, 2005

[66] R. Neu, R. Dux, A. Geier, A. Kallenbach, R. Pugno et al., "Impurity behaviour in the ASDEX Upgrade divertor tokamak with large area tungsten walls," Plasma Physics and Controlled Fusion, vol. 44, no. 6, pp. 811-826, 2002. 
[67] R. Dux, R. Neu, A. G. Peeters, G. Pereverzev, A. Mück et al., "Influence of the heating profile on impurity transport in ASDEX Upgrade," Plasma Physics and Controlled Fusion, vol. 45, no. 9, pp. $1815-1825,2003$

[68] M. Sertoli, C. Angioni, R. Dux, R. Neu, T. Pütterich et al., "Local effects of ECRH on argon transport in L-mode discharges at ASDEX Upgrade," Plasma Physics and Controlled Fusion, vol. 53, no. 3, p. 035024, 2011.

[69] T. Pütterich, R. Dux, M. Beurskens, V. Bobkov, S. Brezinsek et al., "Tungsten screening and impurity control in JET," in Proc. "24th IAEA Fusion Energy Conference”, San Diego, USA, 2012, pp. EX/P3-15.

[70] C. Giroud, M. Oberkofler, D. Douai, G. Maddison, M. Beurskens et al., "Nitrogen seeding for heat load control in JET ELMy H-mode plasmas and its compatibility with ILW materials," in Proc. "24th IAEA Fusion Energy Conference”, San Diego, USA, 2012, pp. EX/P5-30.

[71] L. Aho-Mantila, M. Bernert, J. Coenen, R. Fischer, M. Lehnen et al., "L-mode radiative plasma edge studies for model validation in ASDEX Upgrade and JET," Journal of Nuclear Materials, vol. 438 Supplement, pp. S321-S325, 2013

[72] A. Kallenbach, R. Dux, J. C. Fuchs, R. Fischer, B. Geiger et al., "Divertor power load feedback with nitrogen seeding in ASDEX Upgrade," Plasma Physics and Controlled Fusion, vol. 52, no. 5, p. 055002,2010

[73] R. Neu, A. Kallenbach, M. Sertoli, R. Dux, R. Fischer et al., "Tungsten behaviour in radiatively cooled plasma discharges in ASDEX Upgrade,' Journal of Nuclear Materials, vol. 415, no. 1, Supplement, pp. S322-S326, 2011.

[74] A. Kallenbach, M. Bernert, T. Eich, J. Fuchs, L. Giannone et al., "Optimized tokamak power exhaust with double radiative feedback in ASDEX Upgrade," Nuclear Fusion, vol. 52, no. 12, p. 122003, 2012.

[75] A. Kallenbach, M. Balden, R. Dux, T. Eich, C. Giroud et al., "Plasma surface interactions in impurity seeded plasmas," Journal of Nuclear Materials, vol. 415, no. 1, Supplement, pp. S19-S26, 2011.

[76] G. Tardini, R. Fischer, F. Jenko, A. Kallenbach, R. M. McDermott, et al. "Core transport analysis of nitrogen seeded H-mode discharges in the ASDEX Upgrade," Plasma Physics and Controlled Fusion, vol. 55, no. 1, p. $015010,2013$.

[77] M. Beurskens, J. Schweinzer, C. Angioni, A. Burckhart, C. Challis, et al., "The effect of a metal wall on confinement in JET and ASDEX Upgrade," Invited talk 40th EPS conf. on Plasma Physiks, Helsinki, submitted to Plasma Phys. Control. Fus., 2013.

[78] S. Brezinsek, T. Loarer, V. P. Philipps, H. G. Esser, S. Grünhagen, et al., "Fuel retention studies with the ITER-like wall in JET," Nuclear Fusion, vol. 53, p. 083023, 2013.

[79] R. Dux, E. Fable, A. Kukushkin, A. Loarte, and ASDEX Upgrade team, "Transport of tungsten in the H-mode edge transport barrier of ITER," in Proc. 40th EPS Conference on Plasma Physics, vol. 37D. Geneva: Europhysics Conference Abstracts, 2013, p. P4.143.

[80] O. J. W. F. Kardaun, "On estimating the epistemic probability of realizing $q=p_{\text {fus }} / p_{a u x}$ larger than a specified lower bound in ITER,' Nuclear Fusion, vol. 42, no. 7, pp. 841-852, 2002. 